\title{
A DEMOCRACIA BRASILEIRA E OS JOVENS: COM UMA CURTA INFERÊNCIA GRAMSCIANA.
}

É preciso romper com a credibilidade popular

José Mario Angeli ${ }^{1}$

1. O ponto de partida para refletir a democracia brasileira nos últimos quarto de século pretendendo resolver os problemas da sociedade - a miséria social e da democracia política - pela via capitalista, implica na compreensão do significado do modelo vigente democrático. O comportamento da democracia e suas instituições forjados ao longo do período de ditadura militar na forma de Estado e do regime político, expresso na Constituição de 88 mantém o país "no rol das democracias limitadas" (Saes, 2001).

O superdimensionamento do papel do poder executivo tem à sua disposição instrumentos extraordinários de intervenção decreto-lei (ou medida provisória) - e aplica-os à revelia do parlamento e das demandas sociais. Este método de governo utilizado nos últimos 25 anos configurando aquilo que se convencionou chamar de "regime bonapartista" alimenta o fato de que no Brasil, não há uma correspondência efetiva entre os programas de governo e dos partidos políticos, que formam sua base de sustentação.

De tal sorte que, isto abre espaço para que "segmentos da classe dominante organizem ativamente a sua hegemonia política no seio do bloco no poder" (idem., 130) e faz da política um balcão de negócio onde a consciência democrática das classes subalternas agem como limite e freio das tendências autoritárias

\footnotetext{
${ }^{1}$ Professor de Filosofia Política da Universidade Estadual de Londrina
} 
| 160 |

A democracia brasileira e os jovens...

"naturais" do regime político (Angeli, 2010) o que dispensou uma ruptura institucional pelos sucessivos governos brasileiros.

As várias experiências de regulamentação infraconstitucional - podem ser pensadas tanto naquelas que foram aprovados como a reforma da previdência e aquelas que foram anunciadas e ainda não foram realizadas como a reforma sindical, trabalhista e a universitária dentre outras - dão indiscutíveis indicações de como o espectro político partidário se comporta para ocupar espaço na máquina do governo. O parlamento só faz valer suas prerrogativas para angariar fundos para seus currais eleitorais, mal articuladas nos partidos políticos que os representantes populares usam como partidos de aluguel, além do que, usufruem da administração do orçamento federal fatiando-a entre os caciques dos partidos que sustentam a base do governo.

Se, se considerar o papel central que joga o poder executivo na definição e implementação de mudanças, a orientação, tanto no nível federal como no nível estadual, durante o período que vai da promulgação da Constituição de 88 até hoje, por um lado, elas expressam a adesão a um modelo de desenvolvimento depende e associado do capital internacional. E, por outro, há uma tentativa de diminuição das liberdades democráticas e alguns direitos sociais e políticos, duramente conquistados em anos de lutas contra a ditadura militar, agem como limites "naturais" da ordem capitalista.

2. A permanência dos militares no regime civil fortalece a característica bonapartista das democracias limitadas. Democracias limitadas aparecem acompanhadas por uma incompleta democratização do regime político econômico capitalista. Ele se apresenta penetrado pelas relações capitalistas de produção - um modelo concentrador agrário, industrial, por uma burocracia sindical das centrais de trabalhadores e partidos sem um compromisso ideológico - isto é, tem-se assistido que a democracia brasileira se apresenta como método de chegada ao poder, mais do que um programa, que nutre aspirações de transformação social e que não se esgota em si mesma. Tais democracias se apresentam como uma ruptura entre os eleitores e seus representantes, entre o Poder Executivo e o Poder Legislativo, onde o aumento da autonomia do executivo requenta 
a palavra de ordem da "luta contra as desigualdades" e da "redução das desigualdades". Essa cantilena não leva a crer que as desigualdades são irredutíveis e se renovam constantemente na forma social produtiva capitalista, e, com o risco da ampliação da mercantilização generalizada, ela acaba dissimulando uma anarquia sob as pretensas "leis do mercado" que só obedece á maximização do lucro. Além do que, acomoda-se ao fato de que os indivíduos, reduzidos à preocupação única de sobreviverem, lutam no seu dia a dia, sem que seus sindicatos enfrentem essas adversidades, o que acaba aprofundando ainda mais as desigualdades sociais existentes na sociedade.

Entende-se que a democracia é expressão de conflito, de valores e de interesses, associados aos seus fins animam os atores - as classes, grupos sociais e coletivos de trabalho - de uma sociedade a lutarem por uma nova ordem social produtiva. E, no caso, a democracia limitada tem sido tanto um método para se chegar ao governo e de governar, como uma condição da sociedade civil em que o predomínio da igualdade e da liberdade dos cidadãos, condição sine qua non para a manutenção da ordem democrática, antes mesmo, de uma reestruturação ou ruptura do regime econômico e político.

A compreensão do significado da democracia não se esgota na reestruturação do regime político, porque o projeto de democracia repousa em duas exigências: por um lado, o "conjunto de regras certas do jogo" como afirma Bobbio, permite institucionalmente que os antagonismos sociais não aflorem e caso chegue a resultados incertos nem sempre favoráveis ao interesse das classes dominantes, não coloquem em cheque a governabilidade; por outro pode-se compreendê-la, e para isso os trabalhadores desejam-na, uma vez que ela contém de maneira implícita ou explicita a definição de boa sociedade que dialeticamente desemboca no socialismo (Boron, 1995, p. 66).

Contudo, segundo Boron, há nestas democracias, uma cidadania política abstrata e formal que convive com uma cidadania real concreta marcada pelas desigualdades econômicas. Segundo ele, a cidadania também é expressão de uma forma específica contraditória das classes, forma pela qual a classe dominante/hegemônica é capaz de absorver total ou parcialmente as contradições da sociedade capitalista, assimilada-a ao seu nível 
| 162 |

A democracia brasileira e os jovens...

cultural. Afirma Dias (1996) que a cidadania é mais uma aparência necessária: é uma ideologia constituidora do real (p. 133).

É importante fazer uma clarificação de conflitos e de antagonismos quando se reflete a democracia. Ela permite expressar o real contraditório como espaço de afirmação da ordem capitalista. Ordem compreendida como natural e eterna e porconseguinte apaga todo o conflito e impossibilita/possibilita pensar num outro projeto de sociedade possível. E, logicamente, sua particular concepção de democracia como a única possível, espaço de exclusão das classes subalternas da construção de uma nova ordem, garante o domínio das classes burguesas ou quando não da instrumentalização daqueles que se diziam e se colocavam ao "lado das classes subalternas".

Assim, é nesse sentido, que essa democracia limitada ou burguesa assume a forma do universal, da lei capitalista: todos são iguais perante a lei. A idéia da igualdade formal passa a ser o regulador de todos os mecanismos da sociedade que por sua vez oculta a exploração e a opressão das desigualdades contraditórias. No caso brasileiro essa forma é histórica. Ela é recorrente, pois ao longo de curtos espaços de vida democrática, a sociedade não logrou a alcançar um desenvolvimento compactível com a justiça social para as classes subalternas.

O desenvolvimento brasileiro do pós-guerra descuidou das questões sociais e econômicas dos cidadãos, embora por momento tem-se um certo sucesso econômico e que o futuro poderá ser promissor, Belluzzo lança um alerta que "esse futuro é, sim possível, mas a experiência histórica comprova que o sucesso econômico esta longe de assegurar o progresso social" (2010, p. 52).

Se, por um lado, "o avanço dos direitos sociais", para que os cidadãos possam de fato usufruir dos bens da democracia é a condição mais urgente que interessa à classe trabalhadora; por outro, a contradição se evidencia pelo fato de ter-se um executivo hegemônico, um congresso desmoralizado e os partidos que abandonaram seus programas em troca de um pragmatismo radical voltado para cálculos eleitorais, negam as práticas republicanas essenciais para a democracia, que por conseguinte agrava as condições dos trabalhadores, em virtude da aplicabilidade de um modelo de economia política fundado no 
neoliberalismo freou o avanço de direitos sociais dos trabalhadores.

Certamente, não poderá ter sido essa concepção que levou a Cardoso (2010) se questionar em "para onde vamos?" defendendo a tese do fortalecimento do Estado em detrimento da sociedade civil, ao criticar o autoritarismo popular de Luis Inácio Lula da Silva, mas sim o medo da democracia, até porque a critica advinda de setores conservadores, liberais e sociais democráticas insistem na idéia de crise da democracia ou seja o medo dos trabalhadores de ultrapassarem os limites da democracia formal, por meio de reivindicações salariais, ampliação dos direitos sociais, e sobretudo rebelarem-se contra o capitalismo.

É importante ressaltar que a democracia incompleta é constituída e inserida na forma da sociabilidade capitalista. Ela assume uma forma determinante, expressa em posições e programas diferenciados, que se unificam a partir da perspectiva mais geral das classes que compõe esta sociabilidade, que são as forças antagônicas inerentes à estrutura social e que politicamente plasma uma vida de liberdade e de igualdade para todos.

3. Fala-se da necessidade de avançar na construção da democracia que de fato interessa aos trabalhadores. E, neste sentido, pode-se pensar em Gramsci, teórico da política, capaz de contribuir à questão da democracia. A democracia, segundo Gramsci, "implica em buscar uma ligação com o povo, a nação que se tenha uma unidade necessariamente não servil, devida à obediência passiva, mas uma unidade ativa vigente qualquer que seja o conteúdo desta vida" (Q., 1740). Gramsci vai mais longe ele afirma também que entre a hegemonia e a democracia existe uma imbricação muito forte, pois segundo ele um governo é hegemônico quando existe uma passagem das classes menos favorecidas à participação na economia do país, que constitua ser hegemônica efetivamente. Evidentemente que esta passagem é crucial, pois se trata da passagem do estrutural para a política. A passagem daquilo que Gramsci chamava de sociedade política, integrando sociedade civil, partidos políticos e Estado.

Então, como afirma Dias, significa dizer que ao falar de democracia, "mais do que um desejo moral, ela, é explicitação de conflitos e antagonismo próprio desta sociedade capitalista" 
| 164 |

A democracia brasileira e os jovens...

(idem., p.131), isto é, Dias chama atenção para a compreensão da democracia capitalista uma vez que ela está estabelecida dentro da ordem capitalista. Ela está crivada de contradições e é esta que se tem que entender. Embora tem-se na democracia brasileira, programas de inclusão social que configura de certa forma uma maior distribuição de renda em confronto com governos anteriores, isto não chega a ser garantia de direitos e não significa democratização da economia.

A democracia permite expressar as contradições, como espaço de afirmação da ordem capitalista, e, por conseguinte como espaço de exclusão das classes subalternas como sujeito da história. As classes subalternas aparecem incorporadas à ordem estabelecida pelo Estado cujo domínio é garantido pelas classes burguesas. A ordem conforma os sujeitos e os sustentam no curso de seu cotidiano.

Gramsci afirma que ela "tem um poder taumatúrgico: a conservação das instituições políticas é conferida em grande parte por este poder. A ordem presente se apresenta como algo harmoniosamente coordenado, estavelmente coordenado; e a multidão dos cidadãos hesita e se atemoriza na incerteza do que uma mudança radical pode trazer (...) Forma-se na fantasia a imagem de algo violentamente dilacerado, não se vê a possibilidade de uma nova ordem, melhor organizada, mais vital do que a velha (...) Vê-se apenas a laceração violenta, e o animo temeroso detém-se no medo de perder tudo, de ter diante de si o caos" (Tre principii..., Città Futura, 1917).

A ordem presente na sociedade é tida como um dado "natural" e assim o pensar e praticar o diferente vai sempre contra a ordem, por conseguinte é perigoso, não é natural. A ordem estabelece aquilo que é legal, e, ela é tão mais forte, enquanto ela aparece como natural, isto é, decorrente da natureza humana, sem a qual não poderá viver e se orientar, Dessa forma, a instituições funcionando a contento, elas são mantenedoras da ordem estabelecida, tão natural quanto à ordem intrínseca à natureza humana.

Pode-se dizer que a democracia é um espaço de luta que se estabelece pelos conflitos próprios da sociedade capitalista. Ela é um instrumento de intervenção política, inicialmente no campo da racionalidade social capitalista dominante, e, no seu 
desenvolver histórico, ela irá ampliando as formas de participação, representação e delegação que implica em pensar como as classes se relacionam, até porque, elas tem um embasamento em comum com o conjunto das relações econômicas. Pensar dessa forma, pode-se dizer que a democracia não tem um significado unívoco, antes ela é portadora de ambigüidades, pelo fato dela ser decorrente da estrutura social, bem como, ela não é um método de investigação, pois ela não se esgota em si. Ela é algo insondável, quanto mais se tem, tanto mais se necessita. Num regime em que se há profundas desigualdades sociais é difícil a prática da democracia.

Segundo Lélio Basso, "para que um regime democrático possa se afirmar é necessário que não exista lacerações profundas no tecido social: quando estas se produzem sob o estimulo de tensões muito fortes, de polarizações de classe, quando existem enormes riquezas concentradas em poucas mãos frente às classes populares miseráveis, a democracia não pode subsistir porque ou as massas populares são excluídas do poder, ou se aí participam, servem-se do sistema para subvertê-lo inteiramente, mas neste caso a aspereza da luta conduzirá à ruptura, à destruição, não ao equilíbrio democrático" (1976). Segundo Basso não pode haver democracia se as classes dominantes não consentem em abrir a via da participação do poder ás classes dominadas a não ser sob a adesão desta mesma classe que disciplina a ordem constituída, isto porque a democracia não é congênita com a ordem vigente como entende autores com Bobbio, por exemplo.

A questão, então é saber, como vencer as lacerações profundas existente particularmente na realidade social brasileira? Primeiramente, será preciso romper com a visão estabelecida na sociedade brasileira de que uma democracia meramente política, que definisse um tipo específico de individuo entre o Estado e a Sociedade Civil, cuja caracterização se dá pela liberdade, pluralidade partidária, eleições e aplicabilidade da lei, fosse garantida e se afirmasse no domínio hegemônico da elite burguesa. Essa democracia se dá bem em qualquer regime, pois o individuo aqui se apresenta como uma mera abstração, portador de uma igualdade e direitos iguais para todos, sem levar em conta as condições concretas do individuo. 
| 166 |

A democracia brasileira e os jovens...

Então, será preciso avançar no sentido de romper com os limites das potencialidades representativas no sentido de um autogoverno da sociedade civil, pois a democratização do capitalismo não basta para que as arraigadas estruturas de domínio sobre as que repousam e das quais dependem vitalmente se esfumem como resultado do sufrágio universal e da representação política.

Evitar, assim, o reducionismo político bem como o reducionismo econômico, uma vez que os dois poderão se encontrar sob o manto hegemônico da burguesia. Isto levaria a uma fragmentação e decomposição da realidade social. Realidade esta que tem sido solapada pelo capitalismo. De modo que há sim, um déficit de democracia no governo da sociedade brasileira onde as políticas públicas tem sido cada vez mais focadas em prejuízo da universalidade cidadã (Coggiola, 2008).

É preciso ampliar reformas radicais na sociedade, reduzindo a importância da burocracia, introduzindo novos métodos democráticos para permitir que renasça culturalmente o socialismo. Mas, para tanto a reorganização democrática da produção, deverá ser obra das classes subalternas capaz de refutar qualquer forma de manipulação, seja aquela brutal ou aquela dos fins do capitalismo.

Exemplo mais clarificador parece ser o primeiro emprego, muito decantado na sociedade brasileira, que não decolou. E preciso ter políticas públicas voltadas para nossos jovens. Há na sociedade brasileira grande contingente de jovens desempregados na idade de 15 a 24 anos quando não chegam ao mercado de trabalho aos 28 anos. O emprego de jovens é um desafio político, pois quando essas expectativas são traduzidas em desânimos e frustrações, se tornam mais difícil a estabilidade na sociedade e até mesmo a representatividade e governabilidade democrática.

Imaginemos um jovem chamado a votar, que vota como desempregado e que, anos mais tarde, ao repetir o processo ainda não conseguiu um emprego. Como isso afeta a democracia?

Além disso, existe o problema da relação com a vida profissional, pois quando os jovens não tem oportunidade, dificilmente conseguem quebrar o ciclo de pobreza e trilhar uma trajetória de trabalho decente. Estaremos desperdiçando o talento e a capacidade produtiva necessária para alcançar o crescimento econômico. 
É preciso tomar algumas medidas políticas especificas, $\mathrm{O}$ primeiro emprego não decolou e a profissionalidade além de esbarrar na burocracia dos órgãos de fomentos, o orçamento da união destina-se mais recursos para pagar a divida pública - cerca de $50 \%$ do Produto Interno Bruto, contra 3\% para a educação compromisso assumido com órgãos internacionais com o capital financeiro que inviabiliza o desenvolvimento social do pais e compromete o futuro dos jovens.

A insuficiência do crescimento econômico e a instabilidade estão na base do sistema. Ele provou que ao longo dos anos não é mais suportável e adiável, por isso, a importância de uma política publica que garanta o emprego e assegure os jovens na escola, a recuperação do sistema de ensino de formação profissional articulando e efetivando o direito à formação profissional pós-escolar obrigatória até os 24 anos e a redução da jornada de trabalho se redução de salário com a finalidade de evitar a marginalização profissional.

Então, pode-se falar da democracia do trabalho. Uma verdadeira democracia não é negar a democracia burguesa ou afirmar a democracia limitada, mas para que seja verdadeira é preciso ao mesmo tempo oferecer condições de trabalho qualificado e fazer com que cada cidadão possa se tornar governante, formando-o como afirma Gramsci "como pessoa capaz de pensar, sentir, agir, dirigir ou controlar quem dirige. Assegurar a cada governado a aprendizagem gratuita de modo a formar o trabalhador intelectual democrático e popular que da técnica trabalho chegue a técnica-ciência e à concepção humanística histórica sem a qual se reduz a ser especializado sem se tornar dirigente (especializado mais político) (Gramsci, 1551).

4. O desafio aqui parece ser primeiro em que pese as contingências da democracia bonapartista ou limitada, o recuo das lutas dos trabalhadores e a burocratização acelerada de suas organizações, durante os últimos governos houve um importante crescimento no campo através do MST (Movimento dos Trabalhadores sem Terra) cuja limitação está na legalização pelo INCRA (Instituto Nacional de Reforma Agrária) das ocupações, sem falar que os assentamentos depende dos créditos governamentais, da autolimitação política imposta pelo 
| 168 |

A democracia brasileira e os jovens...

"movimentismo" do próprio MST e da exagerada concentração de terra existente na sociedade.

Um segundo, parece requer ao mesmo tempo, redefinir o conceito de homem que atualmente vigora nas democracias limitadas. Ele é tomado na sua dimensão transcendental e metafísica eminentemente abstrata, como elemento correlato, do conceito tradicional. Isto é de "individuo limitado e bem definido ou individuo limitado à sua individualidade", que segundo Gramsci era "o ponto que precisar reformar" (idem., 1341). Gramsci o concebe como "um bloco histórico de elementos individuais e subjetivos e de elementos de massa, objetivos e materiais com os quais o individuo esta em relação ativa" (idem., 1338).

Gramsci afirma que o século XX criou as premissas de "um homem novo" cuja humanidade não mais assimilável a uma essência ou identidade substancial de um indivíduo, grupo, classe ou nação. Portanto, esse homem coletivo deve ser pensado na sua totalidade orgânica, cujo equilíbrio entre o individuo e coletivo está na capacidade dinâmica de "encontrar a identidade real sob a diferenciação e contradição aparente, e encontrar a diversidade substancial sob a identidade aparente é o mais delicado, incompreendido, mas essencial, dote do crítico das idéias e do historiador do desenvolvimento social" (idem., 2.268).

Segundo Gramsci, significa que a transformação do homem coletivo em um homem ativo de massa, será capaz de superar aquele amorfo elemento de massa que mina o interior das classes subalternas e que poderá colaborar para que elas compreendam a verdadeira dimensão e sua identificação na democracia. Em última instância, a precária condição da política democracia na sociedade brasileira - obviamente consensuada à idéia "do que não há alternativa" e suas consequencias práticas de medidas autoritárias sentidas nos sindicatos e centrais sindicais - só poderá ser resolvida por um movimento extraparlamentar radical de massa. Movimento que deverá sacudir a ilusão da classe trabalhadora instituída nos limites de um capitalismo reformulador. 


\section{Referências}

SAES, D., Republica do capital. Boitempo. São Paulo. 2001.

ANGELI, J. M., "Ano novo: sonhos novos" in Folha de Londrina, Lda. 2010.

BOBBIO, N., Estado, governo e sociedade. Paz e Terra. Rio de Janeiro, 1987.

BORON A., Reflexiones sobre el poder, el estado e la revolución. Espartaco. Córdoba. 2007.

DIAS, E. F., "Cidadania e racionalidade de classe" in Universidade e sociedade. Brasília. 1996

BELLUZZO, L. G., “Não percamos o espírito crítico”, in Carta capital, Janeiro, 2010.

GRAMSCI, A., Quaderni del carcere. Edizione critica dell"Instituo Gramsci di Roma (a cura di ) Valentino Gerratana. Einaudi Editori. Torino 1987.

. "Ter principii, ter ordini". La città Futura. (C. F. 11.2.1917). In. La città Futura. 1917-1918, Einaudi Editori, Torino, 1975.

BASSO, L., Le origini del fascismo. In. Fascismo e antifascismo (19181936): Lezione e testimonianze. Feltrinelli editore. Milano, 1976

CARDOSO, F. H., "Pra onde vamos?" In. Folha de São Paulo. 1. 11. 2009.

COGGIOLA, O., Programas focados no Brasil. In. Mimeo., São Paulo. Junho de 2007. 